\title{
Job enrichment for catalogers
}

\author{
By Marsha Starr Paiste and June Mullins
}

Catalogers

Tufts University

\section{Restructuring the cataloger's work to maximize achievement, responsibility, recognition, and growth.}

uring the summer of 1987, the authors managed a five-month long "linking project." Because of the particular method in which our unified library system operates and because of peculiarities in our library's method of bar coding, we had the task of matching bar-coded circulation cards, often with minimal data, to each of 280,000 MARC records. We planned the overall approach to the project, developed written procedures, maintained statistics, and prepared reports. To accomplish our task, we had some 90 workers (students, temporary workers, and numerous staff members). Although we did not hire or schedule them, we were responsible for training, making daily assignments, revising finished work, providing feedback and formal evaluations.

We set up the work area and attempted to create a pleasant atmosphere. In addition, we provided continuity between day, evening and weekend workers. We acted as liaisons with library branches and departments. A major part of the job was answering questions and devising procedures, especially as it became clear that the circulation clerk who originally typed the book cards had very different concepts of main entry and title proper than a cataloger. As catalogers, we were chosen to head the linking project because of our familiarity with MARC records, ability to interpret bibliographic records, and our awareness of matters involving name authority. The task of matching a physical item to a bibliographic record is the essence of the cataloger's work and this project was a challenging variation from our usual duties. A large part of the work involved sorting problems by type and planning strategy for dealing with each. We determined priorities for these items and assigned this work to appropriate, accurate workers. Again, as catalogers we were particularly well-suited for the job because of our ability to place things within broad categories. For this project, seniority and awareness of local practices were an asset.

For us, the project management was a high point in our careers. We had variety and challenge, and learned a great deal. We developed new capabilities and reinforced old skills. The sense of accomplishment was tremendous as we created a quarter million item-level records in a brief period of time. Our responsibility was great because we had full charge of this project, and its completion was essential to bringing up the automated library system by the targeted fall semester.

These elements of achievement, responsibility, recognition and opportunity for growth are the cornerstones of the theories of job enrichment and job satisfaction developed by Frederick Herzberg.

Frederick Herzberg developed his theories of job enrichment in the late 1950s through interviews with accountants and engineers. Although the validity of his methodology and the accuracy of some of his assertions can be disputed, his theories 
are still discussed some 30 years after their inception. ${ }^{1}$ No discussion of job enrichment fails to mention Herzberg.

The core of his theories are articulated in Motivation to Work and Work and the Nature of Man. ${ }^{2}$ Briefly stated, Herzberg found that factors involved in producing job satisfaction were separate and distinct from the factors that produce dissatisfaction. Satisfaction is derived from aspects of the work itself rather than from the conditions of employment. Assignments devoid of meaningful work will not necessarily yield unhappiness, but the worker will not find satisfaction and productivity may suffer. The opposite of job satisfaction is not dissatisfaction, just lack of satisfaction. The "satisfiers" lie in the work itself. They include achievement, responsibility, recognition, advancement, and opportunity for growth.

Jobs can be enhanced by loading them with these satisfiers. Herzberg was skeptical about "horizontal" loading, that is, merely adding more tasks to a job description. To be meaningful, the loading must divide tasks into "natural work units," with the worker taking responsibility for the whole unit and having autonomy and control over methods and pace. In all instances, the worker needs a sense of "proprietorship" or to feel personally responsible for a meaningful portion of the work. What is accomplished must be through the individual's own efforts. ${ }^{4}$ There must also be built-in sources for feedback.

A most significant contribution to the studies of job satisfaction in libraries is one in which Plate and Stone applied Herzberg's theories in a survey of 238 librarians. ${ }^{5}$ Their findings corresponded to Herzberg's: that the opposite of satisfaction is not dissatisfaction, just lack of satisfaction and that satisfaction arises not from the conditions of labor, but from the content of the work itself. Librarians cited opportunities for advancement and recogni-

${ }^{1}$ Edwin A. Locke, "Nature and Causes of Job Satisfaction," in Handbook of Industrial and Organizational Psychology, ed. Marvin D. Dunnette (Chicago: Rand McNally College Publishing Co., 1976), 1297-1349.

${ }^{2}$ Frederick Herzberg, Bernard Mausner, Barbara B. Snyderman, Motivation to Work, 2nd ed. (N.Y.: John Wiley \& Sons, 1959).

${ }^{3}$ Frederick Herzberg, Work and the Nature of Man (Chicago: World Publishing Co., 1966).

${ }^{4} \mathrm{~J}$. Richard Hackman and Edward E. Lawler III, "Employee Reactions to Job Characteristics," Journal of Applied Psychology Monograph 55 (June 1971): 263.

${ }^{5}$ Kenneth H. Plate and Elizabeth W. Stone, "Factors Affecting Librarians' Job Satisfaction: A Report of Two Studies," Library Quarterly 44 (April 1974): 97-110. tion as being particularly important to them. "However, the fact remains that too many library jobs exist, often in technical services, which are not designed to incorporate the potential for achievement within the job, and offer only infrequent opportunities for recognition from external sources." 6

How can the work of the cataloger be restructured to maximize achievement, responsibility, recognition, advancement, and opportunity for growth?

The cataloger is often an "independent contributor," a worker whose job is professional but not managerial. While the work of cataloging and classification is exacting and challenging, there is also a strong element of routine. A recent study by Lynch and Verdin ${ }^{7}$ suggests that the work of the cataloger, particularly the cataloger without supervisory responsibilities, is less satisfying than that of other librarians. This is because of the routine nature of the work. Other studies have found no significant difference between the level of job satisfaction of catalogers and reference librarians. ${ }^{8}$ Some researchers have concluded that catalogers are less satisfied with particular aspects of their work than other librarians. These include lack of creativity, opportunity to be directly of service to patrons and the community, and variety. ${ }^{9}$ Certain stress-producing factors are particularly present for professionals in technical services. There seems to be a preponderance of paperwork and the feeling of being overloaded is reinforced because technical services work is both easily quantifiable and because backlogs and bottlenecks are often visible. ${ }^{10}$ In a survey by Bunge ${ }^{11} 21.7 \%$ of technical services librarians cited workload as a primary source of stress. Large numbers of technical services librari-

${ }^{6}$ Dana Rooks, Motivating Today's Library Staff: A Management Guide (Phoenix: Oryx, 1988), 139.

${ }^{7}$ Beverly P. Lynch and Jo Ann Verdin, "Job Satisfaction in Libraries: A Replication," Library Quarterly 57 (April 1987): 190-202.

${ }^{8}$ George P. D'Elia, "The Determinants of Job Satisfaction Among Beginning Librarians," Library Quarterly 49 (July 1979): 293.

${ }^{9}$ Steven Seokho Chwe, "A Comparative Study of Job Satisfaction: Catalogers and Reference Librarians in University Libraries," Journal of Academic Librarianship 4(July 1978): 139-143; Susan Faye Burgess, "Job Satisfaction of Reference Librarians and Catalogers," Australian Academic and Research Libraries 13 (June 1982): 73-80; D’Elia, 293.

${ }^{10}$ Shirley W. Leung, "Coping with Stress: A Technical Services Perspective," Journal of Library Administration 5 (Spring 1984): 11-19.

${ }^{11}$ Charles Bunge, "Stress in the Library," Library Journal 112 (September 15, 1987): 47-51. 
ans were also distressed by lack of positive feedback and a feeling of fragmentation $17.4 \%$ in each category). Further, the staff in technical services is particularly prone to involvement in often demoralizing workplace politics because of the "officelike" atmosphere in the department. ${ }^{12}$

Traditional methods of job enrichment for catalogers have concentrated upon individual growth. They may include committee work; research and publication; conference, workshop and lecture attendance; language study and coursework in one's area of specialization or presentation of in-house workshops. Catalogers may also participate in departmental or library retreats of journal reading and discussion groups.

A deeper involvement in the overall work of the cataloging department may provide more genuine and lasting jcb satisfaction. Within the cataloging department, catalogers could be involved in planning, goal-setting and establishing standards. Feelings of achi vvement and of responsibility are encouraged when catalogers set their own priorities and keep their own records, thus generating their own feedback. Experienced catalogers could also play a vital role in interviewing, hiring, and training new library assistants and catalogers. Training provides an opportunity for relearning and refining skills as well as providing variety and a vehicle for recognition. Participation in the selection and training of a good "new hire" promotes a sense of achievement. Departmental accomplishments have a personal significance to the cataloger who plays a role in making them happen.

A general principle of job enrichment is the division of related tasks into units. "A person's feelings of achievement or accomplishment are enhanced if he works on or completes a 'whole' piece of work or if his personal contribution to the whole is clear and visible. Achievement is also enhanced if there is some definite feedback source."13 The division of departmental tasks into natural work units with a single cataloger responsible for each may be the basis for job enhancement. It would effectively remove some of the fragmentation which technical services librarians have cited as a source of stress. The relationship among the tasks in the "work unit" may be one of workflow, of similarity in content or function. Some work units in cataloging are name authority work, series authority work, audiovisual cataloging and processing, management of backlogs, and maintenance of current and accurate subject headings. A cataloger could be assigned a group of tasks with autonomy and responsibility in their execution. Within the "unit" the cataloger could prepare pol-

${ }^{12}$ Leung.

${ }^{13}$ Locke, 1320. icy and procedure manuals, assign duties to support staff, provide training, and participate in staff evaluation. The cataloger could also author any necessary reports and participate in writing departmental reports. Coordination of a work module is especially important in providing continued motivation for the veteran cataloger. In writing about "plateaued" workers in general, one author pointed out, "People on the technical ladder don't have the same status as people on the managerial ladder, because final decisions are made by managers and not technicians. This...reduces the motivational reward value of climbing the technical rungs, and lessens the importance of technical mastery. If it is appropriate, technical people should be given more decision-making authority...professional people especially should be rewarded with challenge, autonomy, and the opportunity to retrain."14 Rockman ${ }^{15}$ in studying job satisfaction in librarians found a high correlation between decision-making, autonomy, and job satisfaction. A study by D'Elia, ${ }^{16}$ who is critical of Herzberg, emphasized the role of good supervision in job satisfaction. A good supervisory climate is one in which the librarian can exercise initiative and professional judgment, autonomy in planning, work with little supervision, and have opportunities to try new methods of performing the job and for receiving recognition for a job well done. These factors are all involved in the management of a work module.

The aspect of responsibility in managing a work module is also stimulation for further professional growth. "Personal accountability for their work, in turn, will motivate librarians to become more knowledgeable, to develop their skills, and to work to their capacity."17

Advancement is an important component of job enrichment. It may come in the form of promotion in rank or into a managerial position. The added responsibility, experience and skills developed through overseeing a "work unit" may prepare the cataloger for such a position. Advancement may also mean developing more sophistication as a cataloger, with an increased appreciation of the nuances involved in good cataloging. A job enrichment program as described above will certainly

${ }^{14}$ Judith M. Bardwich, "How Executives Can Help 'Plateaued' Employees," Management Review 76 (January 1987): 40-64.

${ }^{15}$ Ilene F. Rockman, "Job Satisfaction among Faculty and Librarians: A Study of Gender, Autonomy and Decision Making Opportunities," Journal of Library Administration 5 (Fall 1984): 43-56.

${ }^{16}$ D'Elia, 283-302.

${ }^{17}$ Peter C. Schanck, "Designing Enriched Jobs in Law Libraries," Law Library Journal 78 (Summer 1986): 392. 
encourage this sort of growth.

Within the library the cataloger is the expert in issues of bibliographic control, subject analysis, and MARC formats. That expertise could be tapped by utilizing the cataloger in a consultantlike role beyond the cataloging department. The cataloger could be a resource person for questions and problems for library staff members and patrons. Who better understands the catalog than the cataloger? Participation in bibliographic instruction in the effective use of the catalog may be another job enhancement. The cataloger could also teach other librarians and staff members about the MARC formats, subject headings, and issues of authority control. An experienced cataloger could act as a preceptor for a library school student or a mentor for a library as sistant. These opportunities for growth and recognition should not be overlooked.

Horizontal job loading, or packing a position with a variety of unrelated functions, is generally discouraged by industrial psychologists. However, such job enlargement may have a place in job enrichment for catalogers. In addition to providing variety, job enlargement may provide the cataloger with an overall view of the work of the library and of the interrelationship of tasks. This perspective is useful, particularly if the cataloger also directs a work module, aspires to a management position, or has input into overall decision-making. Such job enlargement may include work in reference and information services, organizing and indexing vertical files, processing reserve materials, acting as bibliographer in an area of specialization, or participation in collection development. "When assigned reference work, technical service staff have an opportunity to discover patron needs, to develop an understanding of library services, and to learn about reference sources and methods. When working on special projects, staff members develop a broad perspective on the library, expand their knowledge of librarianship, and appreciate the needs of their colleagues more."18 Further, "job feedback will be increased because technical services personnel can see firsthand how effective their work of making information readily accessible to library users has been ..."19

Within the library, job enrichment may involve appointment to committees and task forces. Job enlargement, accomplished through horizontal job loading, provides the background which may contribute to effective library problem solving and the development of new procedures and library programs.

Project management may provide an excellent

${ }^{18}$ Schanck, 385-86.

${ }^{19}$ Schanck, 388. vehicle for job enrichment for catalogers. Within a project, tasks are grouped into a tidy work module and there is a sense of personal responsibility. “'Project' implies a beginning and an end, which implies a chance for achievement." ${ }^{20}$ The transition to automated library systems often involves numerous discrete projects and the cataloger's skills make him/her particularly well-suited for directing many of them. For instance, it is the cataloger who understands MARC tagging and its implications for search and retrieval. It is the cataloger who is versed in the complexities of name authority. Catalogers are adept at the critical review of bibliographic records because they frequently edit to correct or enhance copy obtained through bibliographic utilities. Additionally, catalogers are experienced in adapting bibliographic records to meet local needs and in seeking a balance between local needs and national standards.

Currently, most libraries utilize electronic systems and the professional cataloger seems to be found in transitional situations. This is quite evident from the themes of many recent articles such as: catalogers are working at positions soon to be extinct, the job is slowly becoming obsolete, ${ }^{21}$ or cataloger fatigue. It has also been suggested that, for economic reasons, all cataloging work should be done by copy-catalogers, freeing catalogers for other professional duties. Some writers predict comprehensive changes or further narrowing or eliminating the cataloging position. This is predicated upon the dissolution of the "paper files" and to the increased use of "online information retrieval, optical discs, and electronic publishing." 22

However, we believe, as libraries continue to share online resources, the cataloger's proficiencies will be enhanced.

Catalogers have an opportunity to specialize in several specific types of materials, for example, they describe and classify monographs, serials, musical scores, archival items, photographs, maps, graphic materials, microforms, CDs, and other audiovisuals.

In addition to assigning specific subject and alphanumeric categories to the above properties, catalogers wear many library hats; for instance, when problems arise they devise various cataloging

\footnotetext{
${ }^{20}$ Robert N. Ford, Motivation through the Work Itself (New York: American Management Association, 1969), 116.
}

${ }^{21}$ Robert P. Holley, "The Future of Catalogers and Cataloging," Journal of Academic Librarianship 7 (May 1981): 90-93.

${ }^{22}$ Robert D. Stueart, "Libraries: A New Role?" in Books, Libraries and Electronics: Essays on the Future of Written Communication (White Plains, N.Y.: Knowledge Industry Publications, 1982), 93. 
and classification policies for their individual online indexes. They take great care in confirming and determining points of access with an awareness of patron needs. Also, catalogers are frequently called upon to make decisions about such local issues as, which MARC fields should be indexed online for faster direct searching. These considerations may have been overlooked by the system vendor but are most important to the specific needs of music, serials and non-print catalogers. Catalogers also update and maintain a name-authority file for their individual library's automatic system. A certain percent of their job calls for providing original descriptive cataloging, designating added entries, determining analytical entries and annotations. Cataloging librarians also, search and assign subject heading and designate classification numbers. The transition from catalog maintenance to database maintenance is obvious.

Furthermore, these accomplishments combined with other abilities enable these librarians to create new bibliographic records, to edit, input, retrieve, correct and store them online. Because catalogers work intensely with items acquired by the library, they could point out weaknesses in, ${ }^{23}$ or analyze collections; they may also design classification systems for special subject collections.

These days, catalogers have a hand in library institutional policy. For example, in cataloging an educational videorecording series consisting of 3 videocassettes accompanied by one teacher's guide, the cataloger may set a policy of whether to catalog each item separately, or as a group; also whether or not to photocopy the teacher's guide for each cassette in the event two teachers want to use the materials simultaneously. ${ }^{24}$

Catalogers keep a watchful eye over the records of other libraries and may report or edit problem records in a shared resource file. These include records which have contradictory information such as, incorrect form of name, incorrect forms of subject headings and other incomplete or miscoded material. ${ }^{25}$

The skills involved in the various classifying and cataloging strategies of the defunct paper file era, will be utilized by catalogers in expanding, nonconventional roles. These roles could expand upon basic cataloging skills and catalogers could utilize

${ }^{23}$ Kelly Warnken, The Information Brokers: How to Start and Operate Your Own Fee-Based Service, Information Management Series, no.2 (New York: R.R. Bowker, 1981), 18.

${ }^{24}$ Verna Urbanski, ed. "Questions and Answers," OLAC Newsletter 6 (June 1986): 24.

${ }^{25}$ Karen L. Horny, "Quality Work, Quality Control in Technical Services," Journal of Academic Librarianship 11 (September 1985): 206-10. their experience and judgment to develop into information access analysts, systems designers, telecommunications experts or online analyst/ technical resource managers.

Quite prevalent in high-tech employment and outside of traditional libraries, catalogers may be "system designers, mediators, contract negotiators, resource allocators, writers, speakers, fund raisers, researchers, subject experts, collection builders, proposal writers, or telecommunications experts." ${ }^{26}$

The cataloging position of the future is germinating now. One can see several requests within the classified ads section from large academic libraries searching for the library systems analyst, with the description that includes several aspects such as: "developing specifications for new mainframe and microcomputer applications; participating in designing, coding, testing and documenting new modified applications; supporting planning and implementation of new systems; and training endusers in new systems." There was another ad for an Automation Services Department director with the description: "Functions of position include: systems analysis and programming; training and software support; hardware and software evaluation, procurement, and coordination of maintenance; and assist with the implementation and development of the library system." ${ }^{27}$

As some of the current electronic systems become obsolete, and others become more sophisticated, and as new and more advanced systems are made available, the increased improvements and superior capabilities nationally and internationally will replace the older systems. This will require accurate, detail-oriented, experienced catalogers to function as trainers, managers and as library policy developers for these deluxe electronic systems. Catalogers, utilizing the previously mentioned skills, may be called upon to demonstrate their creativity, management ability, independence, and intellectual ability and judgment. These are vital components of job satisfaction and work enrichment.

Above all else, the cataloger's skills reveal a person whose importance is overwhelmingly substantiated in the field. Because it is this person who develops, designs and implements the processes of the subject analysis, classification, organization, editing and expanding the bibliographic records that are crucial to information dissemination.

${ }^{26}$ Miriam Tees, "New Roles for Library School Graduates," Canadian Library Journal 43 (December 1986): 372-76.

${ }^{27}$ Chronicle of Higher Education, September 7, 1988, B35. 


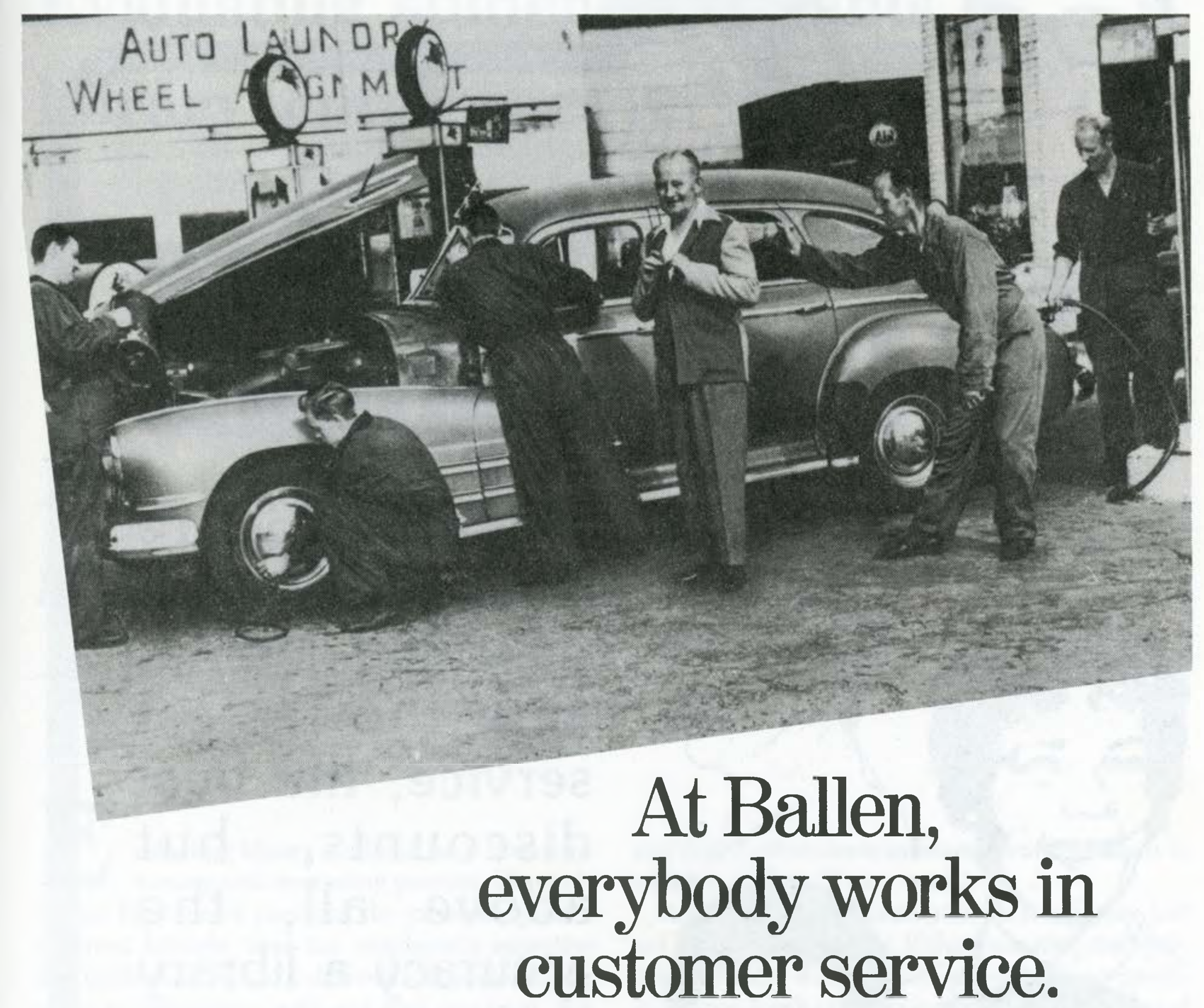

Ballen's commitment to customer service spans from the boardroom to the stockroom. It's what sets us apart from other booksellers, and a big reason why we have the highest fulfillment and lowest return rates in the industry.

Whether you're a large university, small junior college, medical school or special library, we work with you to tailor our services to your specific needs. These include our Approval Program, which is one of the most comprehensive and efficient available. Or our Firm Order Services, which produce the fastest possible response to every order, no matter how obscure the title. And our Continuation/Standing Order Services, in which no volume in any series is ever overlooked.

Our philosophy is simple: the better we serve each customer, the more customers we'll have to serve. To see the difference constant attention to customer service makes, call Ballen at 800-645-5237.

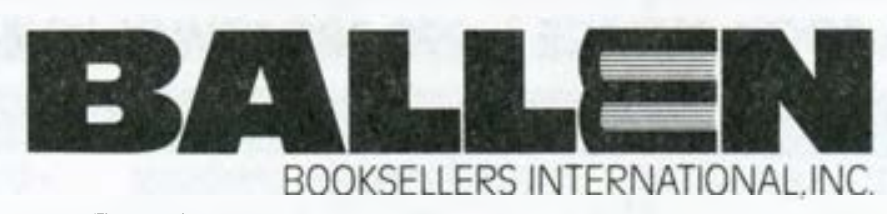

125 Ricefield Lane, Hauppauge, New York 11788 


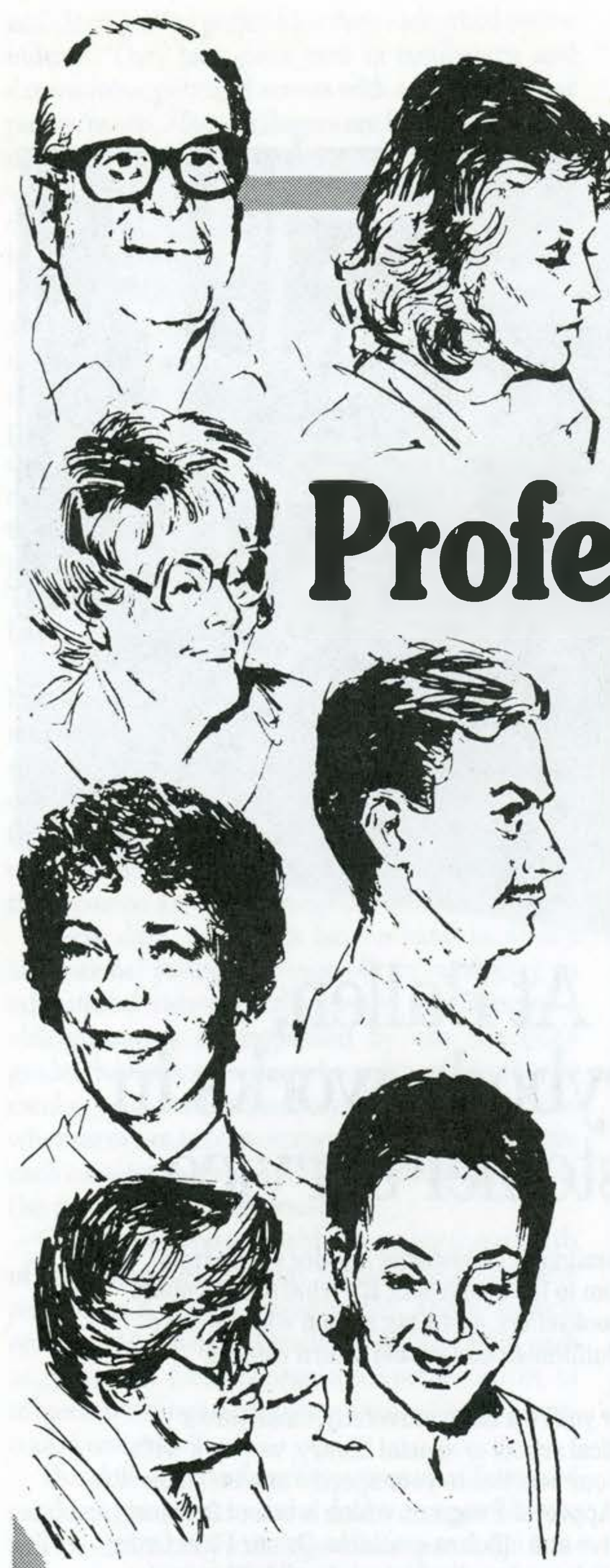

\section{We Are} essionals

We at EBS are dedicated to providing libraries with the fastest service, the best discounts, but above all, the accuracy a library demands.

With all this in your favor you owe it to yourself to try us ...

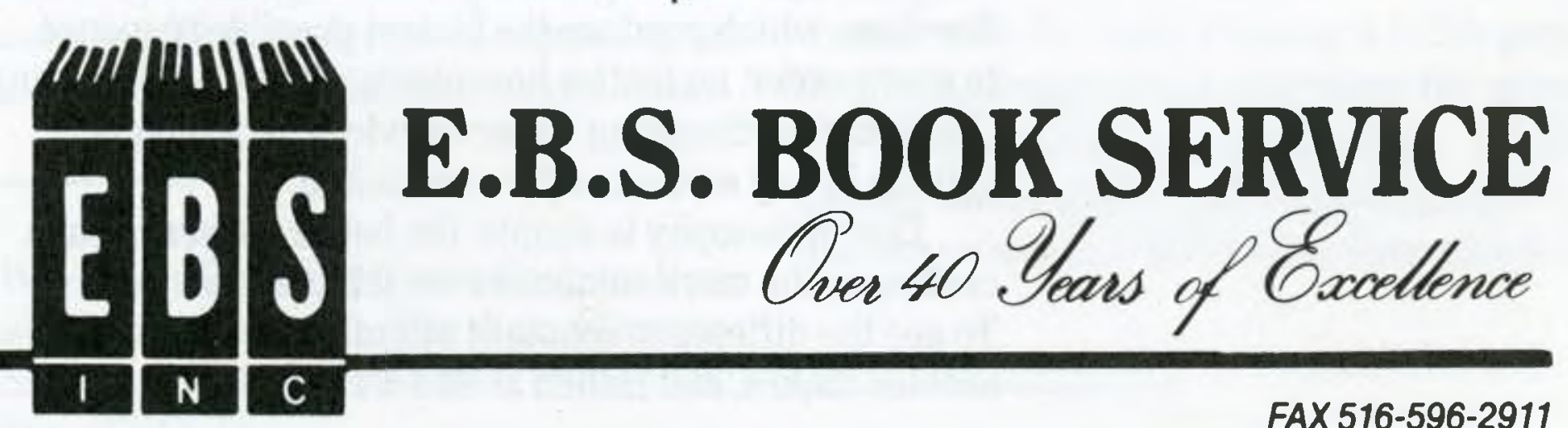

FAX 516-596-2911 E.B.S. INC. BOOK SERVICE - 290 BROADWAY, LYNBROOK, NEW YORK $11563=516-593-1207$ 